\title{
Child psychiatry
}

DOES MOOD IMPROVE IN CHILDREN TREATED FOR SHORT STATURE "-A TIVO YEAR FOI LOW UP STUIOY.

A.M.McGhee, L.Scarth,S.Valentine,H.Gardiner, B.Vange

Dept.of Child Life \& Health. University of Edinburgh.15 Hatton Place.Edinburgh.EH9 1UW.Scotland.

Ninety six children aged 8 to 16 years .attending a regional paediatric growth centre were below the tenth centile for height and had no endocrinological explanation for their short stature. They were randomly allocated to one of seven treatment groups-No Treatment:Placebo:recombinant human Growth Hormone(rhGH): Testosterone:Testosterone plus rhGH:Oxandrolone; Oxandrolone plus rhGH -the first two groups received rhGH from the end of the first year of the trial.

Two self-report measures of mood - the Children's Manifest Anxiety Scale and the Children's Depression Inventory - were completed at baseline and annually thereafter.

At baseline the study group did not differ significantly in either measure by comparison with normal children.At one year there was a non-significant trend towards improvement $(p>0.05)$, but all of the groups receiving active treatment showed improvement over two years and this failed to reach significance only in the group receiving combined Testosterone plus rhGH.

Thus,although the study group were within the normal range at baseline, active treatment of short stature in normal children does appear to be effective in improving mood. Further work is required to determine longer term disadvantages of untreated short stature and whether some subgroups of disturbed children might benefit most.
OVERACTIVITY IN SHORT NORMAL CHILDREN $S$ Valentine, L Scarth, $H$ Gardiner, B Vange, AM McGhee C. Kelnar.H Stirling.

Dept. of Child Life and Health, University of Edinburgh, 17 Hatton Place, Edinburgh. EH9 IUW.*

Children of short stature are often thought to suffer from psychological or behavioural problems, such as poor self esteem or overactivity. However, previous research has mainly been carried out on mixed groups of short children including those with Tumer's Syndrome or Achondroplasia.

The authors took a group of 96 prepubertal short normal children, aged over eight years, who had been referred to a regional paediatric growth centre by their General Practitioners. They were assessed psychologically using six self report questionnaires. The group was reassessed at one yearly intervals for four years, following either no treatment or treatment with synthetic growth hormone, oral oxandrolone, testosterone, placebo, or a combination of growth hormone and either oxandrolone or testosterone.

Baseline analysis of the Conners parent-rated child behaviour questionnaire revealed that $71 \%$ of children scored highly in the hyperactivity section (cut off score $=15$ ). First year follow up analysis (using Chi square), showed a non significant downward trend, $(\mathrm{p}>0.05)$, across all treatment groups, including the no treatment group. Preliminary analysis of second year follow up data shows a continued downward trend. This is most marked in the children $>14$ years, and is not related to drug treatment. At entry into the trial teachers scored $41 \%$ of subjects highly, $(>6)$ in the hyperactivity subsection of the Rutter Teacher Rating Scale (Isle of Wight Study 8.3\% scored highly).

In conclusion, this group of short normal children were perceived as overactive at entry into the trial, both by their parents, and their teachers. This decreased over a period of two years and seemed to be a function of increasing maturity rather than drug treatment. It is unclear why these children should be perceived as more active than normal children. 